\title{
SENTIDOS DE JUVENTUDE NA SOCIOLOGIA E NAS POLÍTICAS PÚBLICAS DO BRASIL CONTEMPORÂNEO
}

\author{
Luis Antonio Groppo \\ Universidade Federal de Alfenas (UNIFAL)
}

\section{SENTIDOS DE JUVENTUDE NA SOCIOLOGIA E NAS POLÍTICAS PÚBLICAS DO BRASIL CONTEMPORÂNEO}

Resumo: $O$ texto analisa as recentes transformações nos sentidos de juventude na sociologia e nas políticas públicas no Brasil, com o objetivo de compreender as origens intelectuais e institucionais destes sentidos. Destacaa constituição do paradigma do jovem como sujeito social, o qual aparece no âmago de um vasto repertório de ideias no espaço público e acadêmico. As fontes bibliográficas indicam um notável imbricamento entre atores e instituições sociais, políticas e acadêmicas, tendo a juventude e os jovens como seu mote. Aborda alguns dos novos referenciais teóricos e problemas de pesquisa sobre juventude, após breve menção a referenciais clássicos na sociologia da juventude. Entre eles, aqueles que tratam da juventude em uma segunda modernidade, ou modernidade tardia, de onde justamente vai surgir o paradigma do jovem como sujeito social, que tão bem vai servir ao discurso oficial das agências supranacionais de desenvolvimento. Por fim, aponta o perigo dos contrabandos e acomodações intelectuais no campo das pesquisas sociais sobre as juventudes, um humilde chamado ao olhar sociológico crítico e reflexivo.

Palavras-chave: Juventude, Sociologia da juventude, Políticas públicas, Sujeito social.

\section{SOME SENSES OF YOUTH IN THE RESEARCHES AND PUBLIC POLICIES OF CONTEMPORARY BRAZIL}

Abstract: The paper analyzes the recent changes in the senses of youth in sociology and public policies in Brazil, with the aim of understanding the intellectual and institutional origins of these senses. Highlights the constitution of a paradigm, the young man as a social subject, which appears in the core of a vast repertoire of ideas in public and academic space. Bibliographical sources indicated remarkable merges between actors and social, political and academic institutions that have the youth as its motto. Approaches some of the new theoretical frameworks and research problems on youth, after a brief mention of classical references in the sociology of youth. Among these new standards, those who treat youth in a second modernity or late modernity, where precisely the paradigm of youth as social subjects will emerge, which will well serve as the official discourse of supranational development agencies). It finishes this text with a digression about the danger of smuggling and intellectual accommodations in the field of social research on the youths, a humble call to critical and reflexive sociological imagination.

Key words: Youth, Sociology of youth, Public policies, Social subject. 
1 INTRODUÇÃO

Com o objetivo de estudar as formas com que se apresentam, atualmente, no Brasil, as práticas socioeducativas direcionadas aos jovens, busquei primeiro compreender os sentidos atribuídos à juventude em nosso país. Desse modo, deparei-me com a constituição de um penetrante paradigma: o jovem como sujeito social. O paradigma do jovem como sujeito social, na realidade, aparece no âmago de um vasto repertório de termos, ideias, slogans e mesmo chavões. Este achado revelador não foi, de modo algum, achado meu, mas fruto das investigações de outros pesquisadores da juventude que cultivam a imaginação sociológica como um saber crítico e radical. Crítico, porque não se deixa levar simplesmente pelas verdades socialmente consolidadas. Radical, porque deseja investigar a fundo, desde suas raízes e estruturas, as ações e interações sociais, mesmo que à custa de escavar muito entulho ideológico que jaz na aparência das coisas. Entre estes investigadores, destaco Regina Magalhães de Souza (2009a; 2009b), em seus trabalhos que deslindam o discurso do protagonismo juvenil e que flagram a matriz que constitui o referido paradigma.

Durante esta busca e com este encontro, na intenção de fundamentar a interpretação das práticas socioeducativas para as juventudes brasileiras atuais, foram realizadas algumas reflexões e digressões que se apresentam abaixo. Elas são fruto de uma revisão bibliográfica sobre as assim chamadas Políticas Públicas de Juventude (PPJs) no Brasil atual. Estas fontes me levaram a considerar um notável imbricamento entre atores e instituições sociais, políticas e acadêmicas, tendo a juventude e os jovens como seu mote. Alguns pesquisadores-chave, em especial, transitaram, desde os últimos anos do século passado, por entre estas instituições, ajudando a constituir versões específicas e locais para o paradigma do jovem como sujeito social, bem como a legitimá-las, sob o respaldo de universidades, órgãos de pesquisa não universitários, agências supranacionais, organizações nãogovernamentais, fundações empresariais, instituições governamentais e mesmo legislativas.

Trato de alguns dos novos referenciais teóricos e problemas de pesquisa sobre juventude, após breve menção a referenciais clássicos na sociologia da juventude. Entre estes novos referenciais, aqueles que tratam da juventude em uma segunda modernidade, ou modernidade tardia (flexível, líquida, reflexiva etc.), de onde justamente vai surgir o paradigma do jovem como sujeito social, que tão bem vai servir ao discurso oficial das agências supranacionais de desenvolvimento, como o Banco Mundial e a Organização das Nações Unidas (ONU).

Finda este texto a digressão sobre o perigo dos contrabandos e acomodações 
intelectuais no campo das pesquisas sociais sobre as juventudes, um humilde chamado ao olhar sociológico crítico e reflexivo, que tantas contribuições trouxe para pensar e transformar a vida social nos últimos tempos.

\section{ALGUNS DOS NOVOS REFERENCIAIS TEÓRICOS E PROBLEMAS DE PESQUISA SOBRE JUVENTUDE}

Os principais paradigmas e referenciais teóricos da sociologia da juventude (e, no meu entender, também, em parte, dos estudos educacionais e psicológicos sobre juventude) podem ser agrupados em três conjuntos de teorias da juventude - com base nos termos e ideias de Tomás Tadeu da Silva (2010) para as teorias do currículo: teorias tradicionais, teorias críticas e teorias póscríticas.

Entre as teorias tradicionais, preocupadas com a integração das novas gerações, ou dos grupos juvenis, na sociedade moderna, destaca-se o tema da socialização e seu antípoda e complemento necessário, o tema do desvio. Elas se desenvolveram em especial na primeira metade do século passado, principalmente nos Estados Unidos. Se foram desenvolvidas, também, no interior da chamada Escola de Chicago e no interacionismo simbólico, seu marco teórico mais influente foi o estrutural-funcionalismo de Talcott Parsons. Parsons (1968), ele próprio, escreveu sobre juventude e educação, mas 0 mais importante livro desta tendência é o de $\mathrm{S}$. N. Eisenstadt (1976), De geração a geração.

As teorias críticas mais fluentes na segunda metade do século XX perguntam sobre a possibilidade de as novas gerações contribuírem com a reforma ou a revolução do sistema social. Elas possuem, como se percebe, ao menos duas tendências, chamadas por José Machado Pais (1993) de corrente geracional e corrente classista. A corrente geracional, para Pais, inclui também o estrutural-funcionalismo, mas em sua perspectiva crítica tem o reformismo de Karl Mannheim (1982) como principal representante. Dentro desta corrente, pode-se incluir a noção de moratória psicossocial (ou simplesmente social), vinda da psicanálise de Erik Erikson (1987). A moratória social concebe o tempo da juventude como o de um lapso temporal, em que há uma certa condescendência da sociedade para que 0 jovem experimente papéis até poder definir sua identidade. Mas moratória social tem o seu outro lado, a saber, a postergação do direito de participação social e política ativa, bem como do exercício da sexualidade (KRAUSKOPF, 2004).

Por sua vez, a corrente classista destaca o tema dos diferentes modos de se viver a juventude, principalmente conforme a classe social, secundariamente, também conforme o gênero. Caracteristicamente, seu referencial marxista heterodoxo faz com que seus autores tenham a revolução - superadora 
do capitalismo - como horizonte ético-político. A principal obra desta corrente foi organizada por Stuart Hall e Tony Jefferson (1982), nas origens dos estudos culturais: Resistance through rituals.

Uma importante derivação das teorias críticas, muito influente na sociologia da juventude praticada na América Latina, foi formada por autores que buscaram compreender os jovens estudantes, especialmente os universitários, por meio de categorias como mobilização e alienação. Mobilização, nos anos 1960, questionando, por exemplo: por que os jovens das classes médias se revoltam contra um sistema que, a princípio, os favorece? (IANNI, 1968; FORACCHI, 1972). Alienação, nos anos 1970, diante do suposto desvario dos jovens de classe média para a acomodação, o consumismo, o uso recreativo de drogas etc. (MARTINS, 1979).

Para os objetivos deste artigo, entretanto, mais importantes são as teorias pós-críticas, originadas no final do século passado. Têm em comum o fato de considerar que a sociedade moderna - como foi descrita pelos estudiosos das teorias estruturalfuncionalistas e outros sociólogos do século $X X$, a saber, como um sistema social integrado e funcional - foi superada, totalmente ou em parte. Há dois tipos de teorias pós-críticas, conforme 0 diagnóstico que fazem da superação da primeira modernidade. 0 primeiro tipo se assenta em teorias pósmodernas e/ou pós-estruturalistas, considerando que viveríamos em um mundo já pós-moderno. 0 segundo tipo, que propõe a tese das socializações ativas e das múltiplas transições juvenis, considera que viveríamos em uma espécie de segunda modernidade. Se o primeiro tipo de teoria pós-crítica exerceu um impacto maior a princípio, inclusive por sua radical negação dos valores modernos, 0 segundo tipo parece ter ganhado espaços maiores nos últimos anos.

As teorias pós-críticas têm, em comum, a concepção de que houve uma ruptura (mais ou menos radical, conforme a tendência) da juventude como ela foi tradicionalmente concebida pela sociologia. Concepção tradicional que, no essencial, nem mesmo as teorias críticas teriam rompido. Esta concepção tradicional de juventude afirmava que: a) os jovens formam um grupo etário bem definido e bem delimitado, com uma associação clara entre cada categoria etária e determinadas funções e instituições sociais infância e juventude associadas à educação/ escola e universidade; maturidade ao mundo do trabalho, empresa, indústria, sindicato e partido; velhice, aposentadoria e previdência social; b) há transição linear à vida adulta, com a juventude terminando com feitos quase simultâneos, como o fim da escolarização, 0 ingresso no mundo do trabalho, o casamento, a formação de um lar próprio e a maternidade/paternidade; c) a socialização se dava por meio da ação das gerações mais velhas sobre as mais novas, ou seja, por 
adultos que guiavam crianças e jovens à plena integração social; d) a moratória social como uma postergação do direito dos jovens ao exercício da sexualidade, do consumo e da participação social plena.

Entre as teorias pós-críticas que apregoam a superação da modernidade, há de se destacar a noção de juvenilização, derivada da obra de Jean Baudrillard (LIBERATO, 2006; BAUDRILLARD, 1972). Segundo esta noção, houve a transformação da juventude em valorsigno, que pode ser comprado por quem deseja ostentar a valiosa juventude e tem recursos para tanto. Inclui-se aqui o tema da Terceira Idade, uma espécie de imposição da juvenilidade aos idosos, como indicam os estudos da antropóloga Guita Grin Debert (1999). Outra noção influente é a de tribos juvenis, oriunda da obra de Michel Maffesolli (1987). Segundo ela, a pós-modernidade é marcada pela multiplicação das socialidades, a formação de tribos efêmeras (com relações emotivas e intensas) e o enfraquecimento das relações sociais institucionalizadas em troca das tribos identitárias.

O segundo conjunto de teorias pós-críticas deriva das teorias da segunda modernidade. Tal movimento teórico parece menos radical que 0 anterior. Esta segunda modernidade é flexível, segundo Harvey (1992), líquida, segundo Bauman (1999) e reflexiva, segundo Giddens (apud BECK; GIDDENS; LASH, 1997). Ele afirma menos a passagem a uma suposta pós-modernidade, e mais uma alteração profunda no interior da própria modernidade, pelos desdobramentos das próprias tendências inerentes a ela.

$\mathrm{Na}$ sociologia da juventude, estas teorias da segunda modernidade ou modernidade tardia inspiram autores europeus como François Dubet (1998), Alain Touraine (1998) e José Machado Pais (1993), e latinoamericanos como Diana Krauskopff (2004), com desenvolvimentos interessantes no Brasil, com Helena Abramo (2005), Marília Spósito (2000), Juarez Dayrell (2002) e Paulo César Carrano (2011) entre outros.

Elas vão afirmar que as transições juvenis são não-lineares e se fazem por meio da socialização ativa. Rompe-se principalmente com a noção tradicional de socialização, tida como uma via de mão única, ao menos desde Durkheim (1978), em que gerações adultas educariam as novas gerações. Estas teorias têm alcançado grande impacto na recente sociologia da juventude feita no Brasil, em especial nas faculdades e programas de pesquisa em educação. É sobre este impacto e reapropriação que pretendo tratar no terceiro tópico.

\section{PARADIGMA DO JOVEM COMO SUJEITO SOCIAL}

Uma das noções sociológicas apropriadas com sucesso no interior das pesquisas sobre juventude, bem como nas próprias PPJs, foi a de que o jovem deveria ser 
promovido a sujeito social. Esta noção aparece principalmente por meio de termos derivados, tais como agente social, ator estratégico de desenvolvimento, protagonista juvenil, jovem voluntário etc. Ela se colocou, a princípio, como contraponto à noção que mais marcara as políticas sociais na América Latina até então: 0 jovem como problema social (LYRA et al., 2002). Ela se apresenta como complemento à noção, oriunda dos movimentos de defesa da criança e do adolescente, do jovem como sujeito de direitos (SPÓSITO; CARRANO, 2007). A noção do jovem como sujeito social evitaria que os jovens fossem tratados de modo similar às crianças e adolescentes, ao se reconhecer a maior capacidade de ação social dos primeiros (DAYRELL, 2003).

De modo esquemático, pode-se dizer que há um movimento de apropriação desta noção, na sociologia da juventude, especialmente a partir da fase mais recente da obra do sociólogo francês Alain Touraine (1998), quando ele passa a focar o tema do sujeito ou ator social. No campo da educação e da juventude, tem se destacado a obra de François Dubet. Mas o próprio Touraine (1988) tem textos em que aplica a noção de sujeito social à juventude e à escola. Em geral, via Dubet, sociólogos da juventude e da educação no Brasil adotaram e fizeram circular tal noção, em especial Juarez Dayrell (2003). Diversas Organizações Não Governamentais (ONGs) voltadas aos jovens, especialmente aquelas de cunho mais progressista, como a Ação
Educativa, também adotaram esta noção e fizeram com que fosse influente nas recentes PPJs no Brasil.

O que nem sempre é claro é o quanto essa noção corrobora as concepções de políticas para juventude vindas dos organismos supranacionais, como os do sistema da ONU e do Banco Mundial (BM). Aparentemente, aquela noção soa como desafio à imposição da agenda das PPJs por estes órgãos e pelo próprio Estado. Olhando mais detidamente, inclusive percebendo a circulação de intelectuais orgânicos influentes por entre estas entidades - universidades, ONGs, organizações supranacionais e Estado - percebe-se que, no seu uso concreto, a noção pouco se contrapõe ao sentido definido pelos poderes maiores às PPJs. Na verdade, 0 próprio Touraine (1998) desenvolve a tese de que as políticas sociais devem promover 0 jovem pobre a ator social na qualidade de consultor do Banco Mundial no Chile.

Há, certamente, outras teorias que concorrem para a predominância, na sociologia da juventude e PPJs atuais, do paradigma do jovem como sujeito social. Para tanto, são apropriadas e adotadas naquilo que reforçam este paradigma. É o caso da teoria da reflexividade de Anthony Giddens, que defende a necessidade de estimular o indivíduo, em um mundo de transformação constante, a desenvolver suas capacidades criativas e de ajuste a situações mutantes, que o permita lidar com os riscos de um mundo social submetido 
ainda mais a contingências (BECK; GIDDENS; LASH, 1997). Outra influência, menos direta, vem da teoria crítica contemporânea, com Axel Honneth e a teoria do reconhecimento. Ela dirá que, em vez da justiça social ou democracia social (luta pela igualdade), as lutas sociais são, sobretudo, contra a degradação e 0 desrespeito, bem como contra a exclusão social. As políticas públicas, destinadas a certos setores sociais ditos vulnerabilizados, em situação de risco, são apresentadas como consequências desta concepção (COSTA, 2010).

Deste modo, percebe-se que mesmo a teoria crítica se rendeu a um dos temas que se tornou soberano nas ciências sociais - e na economia, quando trata de questões sociais: o tema da inclusão/exclusão, no lugar do tema das desigualdades sociais oriundas da estrutura de classes e da exploração pelo capital. Reveladora aproximação, relativa à noção de sociedade que fundamenta tais teorias, se dá entre a teoria crítica e as teses do capital social e desenvolvimento, como as de Amartya Sen (economista que trabalhou para o BM). Para Sen (2000), o cultivo de capital social e o empoderamento de pessoas e grupos empobrecidos podem the dar liberdades (na verdade, capacidades e habilidades). Tais liberdades é que permitiriam a dignificação do sujeito (KERSTENETZKY, 2000). Sen opera a metamorfose da denúncia da desigualdade em debate sobre a exclusão social, e do ideal da igualdade em equidade (DOMINGUES, 2003). Sob estas mesmas bases, Ernesto Rodríguez (2003) desenvolverá propostas para as PPJs, adotando a noção de desenvolvimento social apregoada pelo BM. Sociólogo uruguaio, consultor do BM e ex-presidente da Organização Ibero-Americana de Juventude (OIJ), Rodríguez também será consultor de importante obra publicada pela UNESCO-Brasil (RODRÍGUEZ et al., 2004).

Admiro como Regina Magalhães de Souza (2009a) reconstrói a trajetória da noção do jovem como sujeito ou ator social nas PPJs na América Latina, demonstrando o imbricamento entre textos acadêmicos e documentos emitidos por organismos supranacionais. Primeiro, ela cita 0 artigo de Henry Kirsch na Revista da Comissão Econômica para a América Latina e o Caribe (CEPAL), publicado em 1986. Para Souza (2009a), Kirsch tipifica exemplarmente 0 discurso que se construía sobre a juventude: a conjuntura dos anos 1980 na América Latina requeria outra forma de participação da juventude, menos política (já que as democracias vinham se estabilizando) e mais social, em prol do desenvolvimento (em momento de crise social e econômica no continente). A juventude universitária, por exemplo, não deveria fazer movimento estudantil, mas sim prover recursos humanos e lideranças, ser ator social. Para Souza (2009a), desde então, meados dos anos 1980, 0 paradigma do jovem como ator social passou a 
ser um ponto fulcral na formulação e implementação destas políticas e ações para a própria juventude, ainda que com certas adaptações ao longo do tempo.

Outro termo central, indicando os objetivos desta atuação social, é desenvolvimento. 0 termo aparece nos documentos do BM, das agências da ONU e nos planos dos últimos governos federais no Brasil. Não se trata do desenvolvimento no sentido dado a ele pela própria CEPAL em meados do século $X X$, incentivando intervenções portentosas dos Estados populistas, nos países do Terceiro Mundo, para levar a nação à modernidade, ao capitalismo ou à sociedade de mercado, nos modelos dos países do Primeiro Mundo (o desenvolvimentismo). 0 desenvolvimento aparece agora como chavão para objetivos mais modestos, mas também mais numerosos: refere-se ao cultivo de capacidades individuais (para 0 sujeito tornar-se empregável e socialmente atuante), mas também à valorização de capitais sociais em potencial de uma localidade (a mobilização de recursos e possibilidades locais para que a comunidade encontre a resolução de seus próprios problemas) e, enfim, ao combate à exclusão de indivíduos e grupos da economia formal (promovendo a equidade social) (RODRÍGUEZ et al., 2004).

Uma importante influência, segundo Souza (2009a), foi Alain Touraine. Em meados dos anos 1980, Touraine deixa de tratar dos movimentos sociais como o seu tema principal, passando a se dedicar a compreender o fenômeno que chamou de desmodernização. Touraine, assim como Dubet, não era partidário da tese da desinstitucionalização da vida social, corroída por uma pretensa pós-modernidade (CORROCHANO, 2008) - ainda que Dubet (1998) inicialmente tenha adotado o termo desinstitucionalização. Mais moderados, percebem a dificuldade de as instituições sociais realizarem suas clássicas funções de integração dos indivíduos, em uma sociedade partida, cujos componentes constituíam valores e objetivos distintos e até opostos entre si. Por exemplo, o mundo do consumo prega o prazer imediato, enquanto o mundo da produção exige a racionalidade e o esforço. (TOURAINE, 1998). Nesta sociedade dualista, fragmentada, em desmanche, a luta mais importante não era entre classes desiguais, mas de indivíduos e grupos para não serem excluídos. A única saída parece ser possibilitar aos indivíduos

[...] oportunidades [...] de se tornarem os sujeitos da própria existência. [...] Como vivemos em sociedades de mudança e de comunicação, mas também dessocialização e isolacionismo, devemos consolidar a capacidade de cada pessoa para viver ativamente a mudança. (TOURAINE, 1999 , p. 318, 324). 
Nesse contexto, as políticas de juventude, assim como as escolas, deveriam

[...] incrementar nos jovens a capacidade de se comportarem como atores sociais, ou seja, de modificarem seu entorno social para realizarem projetos pessoais. (TOURAINE, 1998, p. 78).

Deste modo, estas políticas podem contribuir para fortalecer no jovem a capacidade de atuar, escolher, julgar e ter relações sociais. Também, fortalecer no jovem a personalidade para resistir a pressões e à falta de estímulos e recompensas, empoderar o indivíduo como resistência orgânica e mental (alguns diriam, fomentar sua resiliência e autoestima).

Com base em Dubet, Corrochano (2008, p. 3) afirma que viveríamos em um momento de "[...] fragilidade das instituições, quando os indivíduos são convidados a construir de modo cada vez mais solitário o seu percurso." Assistiríamos a um declínio do programa institucional e de mutação das instituições (e não a desinstitucionalização), assim como o declínio de um modo de socialização - em que a socialização era vista como o trabalho de mediação entre valores universais e agentes individuais, ou como a aprendizagem de papéis sociais. Nesta nova configuração, "[...] os adolescentes e os jovens conseguirão, de uma forma mais plena, construir experiências do que interiorizar papéis." (DUBET, 1998, p. 28). Perdeu-se a unidade do mundo social e as instituições não conseguem mais gerar referências rígidas e enraizadas. Cabe ao indivíduo construir tais referências para si.

$$
\begin{aligned}
& \text { Trata-se de um ator } \\
& \text { confrontado com uma } \\
& \text { grande diversidade de } \\
& \text { orientações, isto é, com } \\
& \text { certos antagonismos, e } \\
& \text { que é obrigado a } \\
& \text { construir por si mesmo o } \\
& \text { sentido de sua } \\
& \text { experiência. (DUBET, } \\
& \text { 1998, p. 31). }
\end{aligned}
$$

Segundo Dubet (1998), 0 indivíduo se vê diante de diferentes lógicas da ação social: integração (laços de pertencimento), estratégia (interesses em uma sociedade concebida como um mercado) e subjetivação (confronto, de maneira crítica e autônoma, com a sociedade). Para combinar tais lógicas, entretanto, o indivíduo precisa de um conjunto de recursos materiais e simbólicos, o que pode significar aos mais pobres "[...] novas figuras da dominação e do controle." (CORROCHANO, 2008, p. 28). Como resposta, Dubet (1998) não aponta 0 retorno da força das instituições, nem o triunfo do indivíduo, mas sim a redução da escala institucional e, tal qual em uma orquestra de câmara, os indivíduos são convidados a serem solistas, a saber, empregáveis. Podese completar, solistas de causas pessoais ou locais como voluntários, protagonistas, agentes estratégicos de desenvolvimento, sujeitos sociais. 
Certamente, o paradigma do jovem como sujeito social enseja muitos aspectos positivos para a pesquisa. Ao tratá-los fundamentalmente como sujeitos, o paradigma valoriza a escuta dos jovens. Diversos trabalhos se apresentam como interpretação de vozes de mulheres e homens juvenis (DAYRELL, 2003), outros assumem mesmo a perspectiva de fazer documentários que colhem estas vozes e imagens, por vezes dirigidos pelos próprios sujeitos jovens (BRASIL, 2007). Tal perspectiva considera os jovens como pessoas com autonomia e capacidade decisória, qualidades que os permitem assumir dadas perspectivas e construir certas ideias que não seriam possíveis a pessoas já adultas - com outras relações com as instituições sociais e outras experiências de vida. Há um forte tom de engajamento nas causas dos jovens das camadas populares, com a denúncia das dificuldades socioeconômicas que os têm afetado.

Este paradigma afirma que 0 jovem se torna sujeito mais ativo em sua própria socialização, ainda que com o risco da precariedade e de reversão de conquistas, em especial aos jovens pobres. A partir dele se fazem propostas para educação e políticas públicas, em torno do objetivo de prover 0 jovem de recursos e informações para que eles próprios consigam conduzir suas vidas e dar coerência às diferentes experiências por entre instituições instáveis e incoerentes entre si (família, escola, trabalho, mídia, consumo etc.). Busca assim, primeiro, permitir que o jovem enfrente a precariedade da condição juvenil contemporânea - com 0 auxílio das PPJs. Segundo, contribuir para que o jovem faça a gestão do presente e, terceiro, para que 0 jovem constitua projetos de futuro - desafios os quais as escolas poderiam dar grande auxílio aos jovens.

Há, entretanto, um grande limite do paradigma do jovem como sujeito social. Ele reside nos fortes elos entre as teorias e ideias de Touraine (1998) sobre o ator social e as das agências supranacionais, incluindo pontos nodais como: uma concepção individualista sobre a constituição da sociedade contemporânea; uma percepção do alcance limitado, local, comunitário, da atuação destes atores sociais; uma noção conformista de história e de sociedade, já que o máximo que se pode fazer, no campo das políticas sociais, é civilizar o capitalismo neoliberal, ou seja, não há possibilidade de superar o capitalismo nem mesmo em sua versão neoliberal, versão que favorece a livre concorrência internacional, a reforma do Estado (que rompe com o modelo de bem-estar social), a flexibilização e a precarização do mundo do trabalho e do trabalhador etc. Considerando esta relativa identidade de fundo entre o discurso das agências e o paradigma do jovem como sujeito social, há de se apontar uma série de problemas e riscos neste paradigma quando de sua aplicação na sociologia da juventude. 
Talvez a mais grave seja a subsunção acrítica das pesquisas sociais sobre juventude a concepções e ideologias elaboradas pelos organismos internacionais para as PPJs, em especial o BM e órgãos da ONU (no Brasil, em destaque a Organização das Nações Unidas para a Educação a Ciência e a Cultura (UNESCO)). Diversos chavões que rondam o paradigma do jovem como sujeito social são oriundos destes organismos. Por exemplo, a ideia de protagonismo juvenil, já contida em germe no título do Ano Internacional da ONU da Juventude: Participação, Desenvolvimento e Paz, em 1985 (SOUZA, 2009b). Contudo, a principal formulação desta noção se deu no interior das fundações empresariais brasileiras, que patrocinaram 0 livro do sociólogo (e empresário do mercado social) Antonio Carlos Gomes da Costa: Protagonismo juvenil, publicado em 2000 (TOMMASI, 2005). Por outro lado, se protagonismo juvenil teve grande sucesso no chamado Terceiro Setor, não ganhou o mesmo prestígio no mundo acadêmico (SOUZA, 2009a). Este desprestígio permite à academia dizer que não se engajou nas ideologias das agências supranacionais, criticando a imprecisão do termo - enquanto ideias bem mais fundamentais, oriundas destas mesmas agências, que cabem em outros rótulos supostamente menos ambíguos, adentram 0 discurso acadêmico sobre a juventude.

0 segundo chavão foi empoderamento juvenil, adotado pelo Banco
Mundial nas pesquisas Vozes Jovens / e II e centro da chamada Estratégia de Dakar (Fórum Mundial da Juventude do Sistema das Nações Unidas, em 2002). Na Estratégia de Dakar (apud FURIATI, 2010, p. 41), empoderamento foi descrito como a

\footnotetext{
[...] identificação e a defesa das iniciativas que dão poderes aos jovens para terem controle maior sobre seus destinos individuais e coletivos e sobre sua capacidade de contribuir efetivamente para o progresso da humanidade.
}

Contudo, esta e outras temáticas da Estratégia já estavam quase todas elaboradas pelo Programa de Ação Mundial das Nações Unidas de 1985. Ou seja, a Estratégia não foi criada pela juventude mundial, mas sim foi uma atualização do Programa das Nações Unidas. 0 empoderamento também foi adotado pelo Plano Plurianual do 10 governo Lula (20032007), alinhada à Estratégia do BM para 0 Brasil e também à Meta de Desenvolvimento do Milênio das Nações Unidas (FURIATI, 2010).

Forte também é o termo jovem como ator estratégico do desenvolvimento , como no Plano Nacional de Juventude. É uma ideia/termo/chavão oriundo do BM (2004), novamente com suas pesquisas Vozes Jovens I e II. Para Gonzales e Guareschi (2009), ainda que a noção busque superar a imagem do jovem como problema, preserva a mesma 
intenção de assegurar uma passagem segura para a vida adulta que não ameace a ordem vigente. A diferença é que, agora, o jovem é a solução - solução da exclusão social, ainda que ela mesma ameace estes jovens. Mas a origem do termo são os documentos expedidos entre 1985 e 2005, pela própria ONU ou suas agências, como a CEPAL e a UNESCO.

Concorre para o perigo da adoção acrítica destas concepções, como desenvolvimento social, empoderamento, capital social, desenvolvimento humano, protagonismo juvenil, participação social, voluntariado, ação social, ação comunitária etc., 0 fato de que elas, em geral, são imprecisas e auto-recursivas nas suas definições (CASTRO, 2008).

O segundo risco é a adoção de uma concepção pacificadora e apaziguadora da juventude e da ação social, que desconsidera as possibilidades de transformação social significativa (ou reduz a transformação social a ações com impacto local), nem mesmo para além do modelo neoliberal de capitalismo. Ele está ligado ao risco do uso manipulatório da noção do jovem como sujeito social. Segundo Castro (2008, p. 12) em relação à implementação do Programa Escola da Paz, com coordenação da UNESCOBrasil, no Rio de Janeiro, no início dos anos 2000:

[...] os protagonistas eram objeto de intervenção, e o protagonismo era menos ouvir e conhecer os jovens e mais uma metodologia intervenção social. de

Em uma espécie de pedagogia pacificadora.

Para tanto, realiza-se uma ressignificação de termos como cidadania. A cidadania é transformada em ação social ou comunitária somada à capacidade de buscar a efetivação de seus direitos que, na verdade, são serviços. A participação política é reduzida à consulta sobre o modo como podem operar as PPJs e a participação na execução das ações (via voluntariado, ação comunitária, participação em conselhos, formando uma ONG etc.). Segundo Souza (2009a; 2009b), jovens são chamados a participar de formulação de políticas e de decisões sobre eles. Mas o são por vias - tais como conferências, conselhos, fóruns etc. - que dificultam muito uma participação que leve à ruptura e contestação. Segundo ela, as questões sociais e as soluções já chegam mais ou menos pré-determinadas, assim como 0 quadro analítico para debates se apresenta de modo mais ou menos fechado, o que impede a transgressão. No fundo, a participação dos jovens nas PPJs torna-se uma estratégia de construção de consenso para uma política prédefinida.

Outro risco é o de assumir-se uma concepção despolitizadora de participação ou ação social. A defendida atuação social ou ação social resume-se a defender interesses locais e acesso a serviços, não direitos, e a 
fazer coisas, ou seja, executar tarefas e formalizar medidas já decididas. Não se trata de participação no poder e nos debates decisórios sobre 0 sentido das políticas (SOUZA, 2009b). Afirma-se no campo das PPJs e do Terceiro Setor, em especial pela influência das comunidades epistêmicas internacionais (FURIATI, 2010) (destacando a UNESCO e o BM), que a ação social é o que resta aos sujeitos, inclusive aos jovens, diante de uma sociedade que se fragmentou e se tornou mero aglomerado de atores sociais em atividade e negociação. Certas interpretações sobre o que dizem a respeito do ator social, de Touraine e Dubet, mas também Giddens e mesmo Honneth, cada qual a seu modo, podem levar os pesquisadores, de modo mais ou menos empolgado, a concordar com 0 discurso e a ideologia elaborada sob os auspícios das comunidades epistêmicas internacionais.

O espaço público apresenta-se, por esta perspectiva, como um cenário de atores sociais atomizados por interesses particulares, atores como indivíduos, ONGs, empresas e mesmo o Estado (SOUZA, 2009b). Pergunta, de modo irônico, Tommasi (2007, p. 12),

[...] será, como me disse outro dia um gestor de políticas públicas de juventude, que os jovens brasileiros não precisam mais fazer passeatas na rua porque hoje cada um deles pode criar sua ONG?

Assim ela responde: hoje,

[...] as reivindicações por direitos são substituídas pela expressão de listas de "demandas" específicas, possíveis de ser respondidas por meio da implementação de programas e projetos focalizados, que transformam os demandantes em públicoalvo de alguma ação. (TOMMASI, 2007, p. 14 , grifo da autora).

0 enfoque se torna mais psicossocial que político, mais individualista e direcionado para mudanças de valores e atitudes: para adquirir competências, para inclusão no desenvolvimento, para problemas imediatos e locais.

Os desvios semânticos avançam sobre termos que outrora se tentou colocar à sombra, que precisam ser ressignificados sob as novas roupagens. Por exemplo, a ação social acima concebida, por vezes é identificada, como na publicação oficial sobre a $1^{a}$ Conferência Nacional de PPJ, como participação política, que agora prima por atuar pela inclusão social (CASTRO; ABRAMOVAY, 2009). Até mesmo o termo usado por ativistas anarquistas para definir as estratégias de enfrentamento aos poderes constituídos, a ação direta, ganha novo sentido: ela passaria a identificar a decisão de formar ONGs e atuar como voluntário, em vez de militar no movimento estudantil, em partidos e sindicatos 
(ABRAMO; BRANCO, 2005; também citado por CASTRO; ABRAMOVAY, 2009).

No segundo governo Lula (20072010), o termo jovem como sujeito de direitos ganhou proeminência no discurso oficial. Segundo Souza (2009b), porém, o termo também já tinha sido apropriado pelas ONGs desde os anos 1990 e pelas agências internacionais nos anos 2000. Para estas agências, como anunciado acima, os direitos são traduzidos como serviços - como no livro da UNESCO-Brasil, Politicas de/para/com juventudes (RODRÍGUEZ et al., 2004). Já 0 sujeito (de direitos) é o que faz, ou seja, o que desenvolve seus potenciais, capacidades ou habilidades para contribuir com a solução dos problemas sociais (o desenvolvimento) e que tem a incumbência de assegurar os direitos, ou seja, os serviços (SOUZA ,2009b).

Assim, segundo Furiati (2010), o segundo governo Lula, ao adotar o termo sujeito de direitos, teria apenas atualizado a noção de ator estratégico do desenvolvimento. $\mathrm{Na}$ prática, as PPJs implementadas foram, sobretudo, políticas de inclusão social da juventude pobre (o ProJovem Integrado), juventude que é pensada ainda em uma perspectiva adultocêntrica e estigmatizadora. 0 imaginário do jovem-problema e transgressor continua operando sob as roupagens do discurso do jovem como sujeito social e sujeito de direitos.

\section{4 "CONTRABANDOS" À SOCIOLOGIA DA JUVENTUDE}

Em um de seus brilhantes cursos sobre Karl Marx, Octávio lanni nos ensinou que havia contrabandos orientalistas na obra do economista e filósofo alemão. As ideias preconceituosas e disparatadas sobre a Ásia e as civilizações não-ocidentais, cultivadas no século XIX, foram capazes mesmo de atravessar a couraça lógica das poderosas teorias de Marx (SAID ,1990). Aprendíamos que todos somos filhos de nosso tempo, assim como o foi Marx, mas que também poderíamos identificar e combater tais contrabandos ideológicos por meio do cultivo da boa imaginação sociológica, de que tanto prezava Wright Mills (1959). Também, não significava que devemos simplesmente rejeitar um autor ou mesmo uma tendência teórica por identificarmos nela um ou mais destes contrabandos, já que cada pensador e teoria podem trazer, em contrapartida, ideias e posições criativas e reveladoras sobre nosso tempo e nossos modos de ser.

A adoção do termo contrabando, aqui, deve-se mais à inspiração de Pierre Bourdieu (1988), que em um dos capítulos de 0 poder simbólico, alerta sobre o perigo de que os poderes constituídos (como o Estado e agências financiadoras de pesquisa) passem a determinar o tema, as perspectivas e mesmo os conceitos da pesquisa sociológica. A sociologia corria, assim, o risco de perder sua 
capacidade crítica, de conseguir ir para além das aparências e das explanações do senso comum. O discurso sociológico poder-se-ia tornar mero senso comum refinado (BOURDIEU, 1988).

É este risco que corre a sociologia da juventude na atualidade. Por tempos, a sociologia da juventude no Brasil, ainda que pequena, tratou sobretudo de compreender os movimentos estudantis, como na exemplar obra de Marialice M. Foracchi (1972). Nos aos 1970 e 80, o porquê destes movimentos terem perdido sua força.

A partir dos anos 1990, a produção das ciências sociais sobre juventude cresce muito, mas seu tema é outro, suas preocupações são diferentes. Destaca-se 0 tema das PPJs. Tanto a noção do jovem como sujeito social, quanto a nova noção de desenvolvimento, mas também 0 termo políticas públicas, desembarcam na América Latina nos anos 1980, por meio da ONU e BM. No Brasil, com maior frequência, a partir dos anos 1990.

Pablo Ortellado (2013) tem afirmado que as instituições universitárias de pesquisa ficaram por muitos anos quase que completamente desatentas para com os movimentos juvenis, que continuaram a acontecer, sobretudo o movimento antiglobalização (no final do século passado e no início do presente) e o Movimento Passe Livre (MPL). É claro que houve trabalhos importantes sobre o assunto, como o de Janice
Tirelli P. de Sousa (1999), mas eles foram bem minoritários diante do grosso da produção. Isto explica o ar de espanto de muitos cientistas sociais diante das Jornadas de Junho de 2013, assim como a interpretação de que elas foram fruto de uma suposta espontaneidade, ignorando a história de organização e atuação de coletivos juvenis como o MPL. O jovem ativista das Jornadas de Junho é o outro jovem com quem se estranham as ciências sociais de hoje - enquanto que a sociologia da juventude dos anos 1960 e 70 tinha como sujeito ausente os jovens das camadas populares.

Nos dias atuais, falar da juventude passou a ser falar de PPJs. E juventude passa a ser mais motivação para falar de políticas públicas, mais do que da própria juventude em si - e mais do que propriamente realizar PPJs. Vide lá, novamente, o livro oficial da 1a Conferência Nacional de PPJs (CASTRO; ABRAMOVAY, 2009). Ele reconhece, na introdução das organizadoras, que os diferentes sujeitos que participaram da Conferência tendiam a tornar equivalentes PPJs e juventude, dado que sempre chamaram - evento de Conferência Nacional de Juventude. De modo revelador, vários textos que comentam as PPJs também chamam o evento de Conferência Nacional de Juv entude (SOUZA, 2011).

Durante os governos Lula (20032010), a PPJ mais forte foi o ProJovem, de caráter fortemente inclusivo, talvez assistencialista, tentando combinar 
transferência de renda, permanência escolar, oficinas socioeducativas e ação comunitária (SPÓSITO, 2008) - com base no modelo do Agente Jovem, implementado no $2^{\circ}$ governo Fernando Henrique Cardoso (2006-2009). Como visto, há uma distância entre o discurso (jovem como cidadão ativo ou mesmo protagonista) e a prática (mais assistencialista, adultocêntrica e com base no imaginário do jovem problema).

Entretanto, as instituições universitárias de pesquisa, a dita academia, têm adotado amplamente as noções, categorias e ideologias disseminadas pelos que pautaram a atual feição das PPJs e do discurso legitimador delas, como BM, UNESCO, CEPAL e a OIJ. Por vezes, adotando termos mais refinados, se fazem presentes as noções disseminadas pelas comunidades epistêmicas internacionais, com fortes reverberações no chamado Terceiro Setor e nos governos federal e locais, noções como protagonismo juvenil, voluntariado, inclusão social, desenvolvimento social, ação social, jovem como solução etc.

Isto não significa negar a importância de pesquisas sobre as PPJs e mesmo sobre estas categorias e ideologias. Ao contrário, isto é fundamental, mas, para tanto, é necessário a capacidade de se distanciar criticamente, o que pode permitir posterior reaproximação propositiva para a transformação da realidade, em vez da aceitação passiva ou disfarçada do discurso oficial. O próprio termo Observatório, que denomina importantes núcleos de pesquisa sobre a juventude em universidades brasileiras, tem sua origem, ou ao menos a sua disseminação, naquelas comunidades epistêmicas internacionais. Está presente, por exemplo, em artigo propositivo de Ernesto Rodríguez (2003), que foi consultor do BM e presidente da OIJ.

Isto também não significa negar a força das obras de autores como Alain Touraine e François Dubet, nem a validade de diversos aspectos do paradigma do sujeito social (e do jovem como sujeito social). Se Octavio lanni, notável marxista brasileiro, nos recomendava ler com distanciamento crítico a obra de seu mestre, compreendendo a inserção dela em um dado contexto histórico e político, o mesmo é preciso fazer com estes grandes inspiradores da sociologia da juventude contemporânea. Lembrar, inclusive, que alguns deles, lá fora e aqui, não são apenas pesquisadores acadêmicos, mas também consultores e assessores destas agências internacionais. Isto não é necessariamente um problema, por si só não deve ser condenado. A ressalva é quando, como neste caso, a imaginação sociológica deixa de sê-la, pois se submete a categorias, noções e ideias que ficam a salvo da análise crítica.

\section{CONCLUSÃO}

Penso que há uma via interessante de compreender as juventudes 
brasileiras - mas, jamais uma fórmula pronta destinada a tudo responder. Trata-se do olhar dialético sobre as juventudes. Uma mirada histórica sobre as sociedades modernas pode perceber os contornos da condição juvenil como dialética, ou seja, as juventudes se movem, contraditoriamente, entre processos de institucionalização e autonomia dos jovens. A dialética da juventude se dá pela presença de elementos contraditórios no interior das instituições criadas para a suposta socialização dos jovens, como as escolas. Estes elementos sempre colocaram o que se definiu como oficial em estado de contestação, em estado de possível superação. Tais elementos são oriundos da possibilidade de autoconstrução, pelos jovens, de formas de pensar e agir diversas daquelas desenhadas institucionalmente - ainda que esta proximidade entre tantos sujeitos jovens tenha sido proporcionada, justamente, pelas instituições. As juventudes na sociedade moderna sempre estiveram envoltas em tensões, conflitos, rearranjos institucionais e resistências contra-instituintes. As juventudes foram e são parte das lutas sociais para estabelecer o domínio de certos grupos sociais, seu projeto político e visão de mundo. E parte das lutas para resistir a este domínio. (GROPPO, 2000, 2004).

Este olhar dialético pode ajudar a entender não apenas os sentidos destas novas institucionalidades sobre as juventudes, oriundas das PPJs, mas também dos sentidos das Jornadas de Junho de 2013 e de outras mobilizações de coletivos formados por jovens. Também, compreender a possível relação entre eles, as PPJs e as Jornadas de Junho, a institucionlidade e a revolta, ou seja, analisar a sua unidade contraditória. Depois de tantos anos falando oficialmente sobre juventude e PPJs, propondo uma dada participação social dos jovens em favor do desenvolvimento (pessoal e social), eis que nos deparamos com coletivos juvenis organizando manifestações que arrastaram milhares de pessoas em grandes cidades do país, discutindo questões amplas e profundas relacionadas à estrutura socioeconômica e política. Tão paradoxal quanto, a inserção posterior de pautas e sujeitos sociais pouco progressistas, como o nacionalismo ufanista e grupos direitistas que, em São Paulo, chegaram a entrar em conflito com vários dos manifestantes originais.

Após tantos anos deixando-se levar pelos discursos oficiais das agências internacionais e dos governos sobre a juventude, a dita academia surpreendeu-se com ações juvenis coletivas muito politizadas e radicalizadas, que ganharam uma dimensão inesperada. Quiçá a sociologia da juventude repense seus fundamentos e práticas. Não para que consiga prever fenômenos como as Jornadas de Junho de 2013 (e a sociologia não é mesmo a arte da previsão, assim como acontecimentos como este não são previsíveis), mas para que não se surpreenda 
com o que pensam e fazem os jovens reais, de carne e osso.

\section{REFERÊNCIAS}

ABRAMO, H. W. Condição juvenil no Brasil contemporâneo. In: BRANCO, P. P. M. (Orgs.). Retratos da juventude brasileira: análise de uma pesquisa nacional. São Paulo: Perseu Abramo/Instituto Cidadania, 2005. p. 37-72.

; BRANCO, P. P. M. (Orgs.). Retratos da juventude brasileira: análise de uma pesquisa nacional. São Paulo: Perseu Abramo/Instituto Cidadania, 2005.

BANCO MUNDIAL. Vozes jovens: um olhar das Organizações e Movimentos de Juventude sobre o Brasil do século XXI. Brasília, DF, 2004.

BAUDRILLARD, J. Para uma crítica da economia Política do signo. São Paulo: Martins Fontes, 1972.

BAUMAN, Zygmunt. Globalização: as conseqüências humanas. Rio de Janeiro: Jorge Zahar Ed., 1999.

BECK, U.; GIDDENS, A.; LASH, S. Modernização reflexiva: política, tradição e estética na ordem social moderna. São Paulo: EdUnesp, 1997.

BOURDIEU, P. 0 poder simbólico. Lisboa: Difel, 1988.

BRASIL. Ministério da Educação. Secretaria de Educação a Distância. Programa Salto para o Futuro. Boletim do Observatório Jovem, Niterói, n. 24, nov. 2007. Debate - Juventudes em rede.

CARRANO, P. Políticas públicas de juventude: desafios da prática. In: PAPA, F. de C.; FREITAS, M. V. de. (Orgs.). Juventude em pauta: políticas públicas no Brasil. São Paulo: Petrópolis, 2011. p. 235-249.

CASTRO, J. P. M. e. Protagonismo juvenil e os novos modelos de políticas públicas. In: REUNIÃO BRASILEIRA DE ANTROPOLOGIA, 26., 2008, Porto Seguro. Anais... Porto Seguro: ABA, 2008. Disponível em:<http://www.abant.org.br/conteudo/ANAIS/C D_Virtual_26_RBA/foruns_de_pesquisa/trabalh os/FP\%2009/joao\%20paulo\%20macedo\%20e \%20castro.pdf>. Acesso em: 10 maio 2013.

M. G.; ABRAMOVAY, M. Quebrando mitos: juventude, participação e política: perfil, percepções e recomendações dos participantes da 1a Conferência Nacional de Políticas Públicas de Juventude. Brasília, DF: RITLA, 2009.

CORROCHANO, M. C. 0 trabalho e sua ausência: narrativas de jovens do Programa Bolsa Trabalho no município de São Paulo. 2008. 87 f. Tese (Doutorado em Educação) Faculdade de Educação, Universidade de São Paulo, São Paulo, 2008.

COSTA, J. C. de C. Desigualdade social, modernidade periférica e reconheciimento: a teoria social pós-crítica e o programa PROJOVEM. Ciências Sociais Unisinos, São Leopoldo, v. 46, n. 2, p. 156-167, maio/ago. 2010.

DAYRELL, J. O jovem como sujeito social. Revista Brasileira de Educação, Rio de Janeiro, n. 24, p. 40-52, set./dez. 2003.

O rap e o funk na socialização da juventude. Educação e Pesquisa, São Paulo, v. 28, n. 1, p. 117-136, jan./jul. 2002.

DEBERT, G. G. A reinvenção da velhice: socialização e processos de reprivatização do envelhecimento. São Paulo: EdUSP/Fapesp, 1999.

DOMINGUES, J. M. Amartya Sen, a liberdade e o desenvolvimento. In: Do Ocidente à modernidade: intelectuais e mudança social. Rio de Janeiro: Civilização Brasileira, 2003. 
DUBET, François. A formação dos indivíduos: a desinstitucionalização.

Revista

Contemporaneidade e Educação, [S. I.], ano 3, v. 3, p. 27-33, 1998.

DURKHEIM, É. Educação e sociología. 10. ed. São Paulo: Melhoramentos, 1978.

EISENSTADT, S. N. De geração a geração. São Paulo: Perspectiva, 1976.

ERIKSON, E. Sociedad y adolescencia. 11. ed. México: Siglo Veintiuno, 1987.

FORACCHI, M. A. M. A juventude na sociedade moderna. São Paulo: Pioneira/Edusp, 1972.

FURIATI, N. M. de Á. Juventude e Estado no Brasil: a lógica constituinte do Conselho Nacional da Juventude no Governo Lula. 2010. 340 f. Tese (Doutorado em Sociologia) Instituto de Ciências Sociais, Universidade de Brasília, Brasília, DF, 2010.

GONZALES, Z. K.; GHARESCHI, N. M. de F. O protagonismo social e o governo dos jovens. Revista Latinoamericana de Ciências Sociais, Niñez y Juventud, Manizales, v. 7, n. 1, p. 37-57, jan./jun. 2009.

GROPPO, L. A. Dialética das juventudes modernas e contemporâneas. Revista de Educação do Cogeime, São Paulo, Ano. 13, n. 25, p. 9-22, dez. 2004.

Juventude: ensaios sobre sociologia e história das juventudes modernas. Rio de Janeiro: DIFEL, 2000.

HALL, S.; JEFFERSON, T. (Orgs.). Resistance through rituals: youth and subcultures in postwar Britain. Londres: Hutchinson; Birmingham: Universidade de Birmingham, 1982.

HARVEY, D. Condição pós-moderna: uma pesquisa sobre as origens da mudança cultural. São Paulo: Loyola, 1992.
IANNI, O. O jovem radical. In: BRITTO, S. de (Org.). Sociologia da Juventude. v. I. Rio de Janeiro: Zahar, 1968. p. 225-242.

KERSTENETZKY, C. L. Desigualdade e pobreza: lições de Sen. Revista Brasileira de Ciências Sociais, São Paulo, v. 15, n. 42, p. 113-122, fev. 2000.

KRAUSKOPF, D. Comprensión de la juventud: el ocaso del concepto de moratoria psicosocial. Jovenes: Revista de Estúdios sobre Juventud, México, ano 8, n. 21, p. 26-39, jul./dez. 2004.

LIBERATO, L. V. M. Expressões contemporâneas de rebeldia: poder e fazer da juventude autonomista. 2006. 269 f. Tese (Doutorado em sociologia) - Programa de PósGraduação em Sociologia Política, Centro de Filosofia e Ciências Humanas, Universidade Federal de Santa Catarina, Florianópolis, 2006.

LYRA, J. et al. A gente não pode fazer nada, só podemos decidir sabor de sorvete: adolescentes - de um sujeito de necessidades a um sujeito de direitos. Cadernos Cedes, Campinas, São Paulo, v. 22, n. 57, p. 9-21, ago. 2002.

MAFFESOLI, M. 0 tempo das tribos: 0 declínio do individualismo nas sociedades de massa. Rio de Janeiro: Forense-Universitária, 1987.

MANNHEIM, K. O problema sociológico das gerações. In: FORACCHI, M. M. (Org.). Mannheim. São Paulo: Ática, 1982. p. 67-95. (Coleção Os Grandes Cientistas Sociais, n. 25).

MARTINS, L. A Geração Al-5. Ensaios de Opinião, Rio de Janeiro, n. 3, 1979.

MILLS, C. W. A Imaginação Sociológica. Rio de Janeiro: Zahar, 1959.

ORTELLADO, P. Reflections on the Free Fare Movement and other New Social Movements. Mediações: Revista de Ciências Sociais, Londrina, v. 18, n. 2, p. 110-117, 2013. 
PAIS, J. M. Culturas juvenis. Lisboa: Imprensa Nacional, 1993.

PARSONS, T. A classe como sistema social. In: BRITTO, S. de (Org.). Sociologia da juventude. v. 3. Rio de Janeiro: Zahar, 1968. p. 47-76.

RODRÍGUEZ, E. Políticas Publicas de juventud en América Latina: de la construcción de espacios específicos, al desarrollo de una perspectiva generacional. Revista Latinoamericana de Ciencias Sociales, Niñez y Juventud, Manizales, v. 1, n. 2, p. 3757, jul./dez. 2003.

et al. Políticas públicas de/para/com as juventudes. Brasília, DF: UNESCO, 2004.

SAID, E. W. Orientalismo: o oriente como invenção do ocidente. São Paulo: Companhia das Letras, 1990.

SEN, Amartya. Desenvolvimento como liberdade. São Paulo: Companhia das Letras, 2000

SILVA, T. T. da. Documentos de identidade: uma introdução às teorias do currículo. 3. ed. Belo Horizonte: Autêntica, 2010.

SOUSA, J. T. P. de. Reinvenções da utopia. A militância política de jovens nos anos 90 , São Paulo: Hacker, 1999.

SOUZA, P. L. A. de. A participação nas políticas públicas de juventude: caminhos trilhados e caminhos a construir. In: PAPA, F. de C.; FREITAS, M. V. de (Orgs.). Juventude em pauta: políticas públicas no Brasil. São Paulo: Petrópolis, 2011. p. 30-45.

R. M. de. O conceito de protagonismo juvenil. In: ESPINDULA, B. (Org.). Protagonismo da juventude brasileira: teoria e memória. São Paulo: Instituto Arte Cidadania/Centro de Estudos e Memória da Juventude, 2009a. p. 10-24.

Protagonismo juvenil: o discurso da juventude sem voz. Revista Brasileira de Adolescência e Conflitualidade, [S. I.], v. 1, n. 1, p. 1-28, 2009b.

SPÓSITO, M. P. Algumas hipóteses sobre as relações entre movimentos sociais, juventude $e$ educação. Revista Brasileira de Educação, Rio de Janeiro, n. 13, p. 73-94, mar./abr. 2000.

Juventude e educação: interações entre a educação escolar e a educação nãoformal. Educação e Realidade, Porto Alegre, v. 33, n. 2, p. 83-98, jul./dez 2008.

; CARRANO, Paulo César Rodrigues. Juventude e políticas públicas no Brasil. In: FÁVERO, Osmar et. al. (Orgs.). Juventude e contemporaneidade. Brasilia, DF: UNESCO/MEC/ANPEd, 2007. p. 179-215.

TOMMASI, L. de. Abordagens e práticas de trabalho com jovens: um olhar das organizações não governamentais brasileiras. Jovenes: Revista de Estúdios sobre Juventud, México, v. 9, n. 22, p. 246-267, ene./jun. 2005.

Jovens brasileiros, espaços e tempos de participação política. Boletim do Observatório Jovem, Niterói, n. 24, p. 12-20, nov. 2007. PGM 1 - Espaços e tempos de participação; Debate - Juventudes em rede Programa Salto para o Futuro/TV Escola.

TOURAINE, A. Juventud y democracia en Chile. Última Década, Valparaíso, n. 8, p. 7187, mar. 1998.

Poderemos viver juntos?: iguais e diferentes. Rio de Janeiro: Vozes, 1999.

\section{Luis Antonio Groppo \\ Cientista Social \\ Doutor em Ciências Sociais pela Universidade Estadual de Campinas (UNICAMP) \\ Professor da Universidade Federal de Alfenas (UNIFAL) \\ E-mail: luis.groppo@gmail.com}

Universidade Federal de Alfenas - UNIFAL

Rua Gabriel Monteiro da Silva, 700, Centro - Alfenas/MG CEP: $37130-000$ 